\title{
Using causal models to evaluate Force Generation options
}

\author{
$\underline{\text { Denis R. Shine }}^{1}$, Julia Knoll ${ }^{1}$ and Thang Cao ${ }^{1}$ \\ 1. Defence Science and Technology Group \\ Email:denis.shine@dst.defence.gov.au
}

\begin{abstract}
The Australian Army maintains a Force Generation system which allows for a portion of its forces to maintain a high level of readiness for operations while allowing for time to train and recuperate. The current Force Generation system, based on Plan Beersheba, has been in operation for approximately a decade, but the challenges posed by Accelerated Warfare and future Army modernisation programs require that the Force Generation system adapt also. Defence Science and Technology Group (DSTG) was engaged to rapidly assess the trade-offs between several Force Generation system options, and through wide stakeholder engagement, built the Force Generation Options Assessment Model, a hybrid Bayesian Belief Network and Utility model.

Stakeholders were engaged across the Army in a two-phase process. The first phase was model derivation, where we elicited the critical factors influenced by the Force Generation system, as well as their influences and linkages. This allowed for the construction of a causal model, albeit unpopulated. The second phase was model data collection, where the conditional probability tables were elicited for all factors from a wide range of Subject Matter Experts.

This paper describes the imperatives behind reviewing Army's Force Generation system, the DSTG approach for assessing Force Generation system options, the critical factors and measures which underpinned the assessment and the future developments planned for analytical conduct.
\end{abstract}

Keywords: Army, Force Generation, causal models, Bayesian Belief Networks 


\section{INTRODUCTION}

The Australian Army's mission is to prepare land forces for war. This requires a high level of preparedness in terms of both equipment and training which is only sustainable for limited periods of time. Therefore, Army maintains a Force Generation system where different force elements are at various states of readiness, sequenced such that some portion of the Army is prepared for deployment at any particular instance.

For the past decade, the Army's Force Generation system has been based on Plan Beersheba, which reorganised $1^{\text {st }}, 3^{\text {rd }}$ and $7^{\text {th }}$ Brigades into functionally identical Multi-Role Combat Brigades (MCB) and established a 36month Force Generation cycle (Figure 1), where each MCB at any point in time sits in one of three 12-month phases: Ready, meaning ready for combat operations, Readying, meaning preparing to be ready for combat operations and Reset, where soldiers can conduct individual training and take longer term leave. For each $\mathrm{MCB}$, the phases are offset such that at any point in time, one MCB is ready for combat operations, and can be sustainably replaced by a like MCB every 12 months.

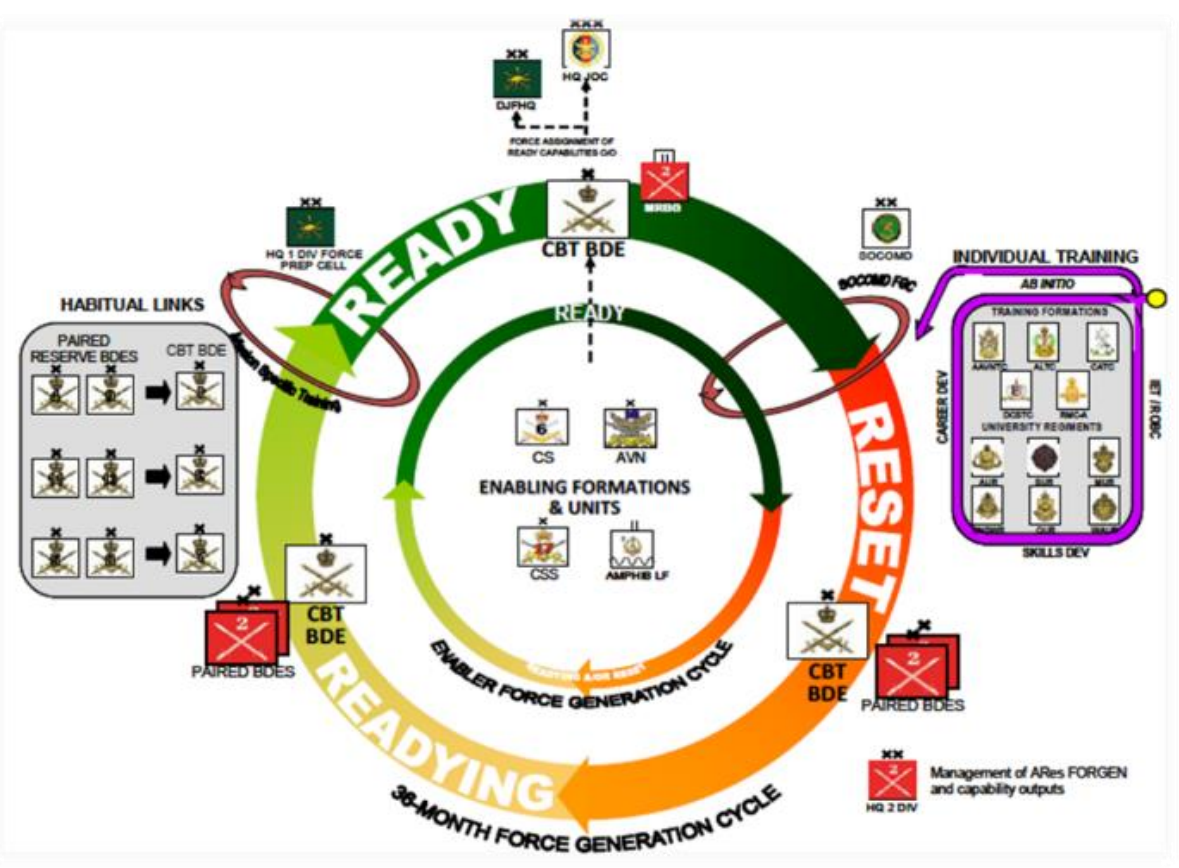

Figure 1. Plan Beersheba Force Generation Cycle

For reasons to be described, the Plan Beersheba model has been determined to be in need of revision to meet Army's future needs. Defence Science and Technology Group (DSTG) was engaged to assess the trade-offs between future Force Generation options and this paper describes the approach undertaken to achieve this.

\section{PROBLEM STATEMENT}

Among the many drivers of Plan Beersheba were two key imperatives; the need for sustainably deployable force elements and the need for more effective combined arms training in Australia. The reform drew upon the lessons of Army's long-term engagements in the Middle East over the previous decade. As these engagements have waned and in light of other modernisation initiatives within the Army, this Force Generation system is increasingly out of step with Army's needs and therefore alternative approaches are now being considered.

Cognisant of these challenges, as early as 2018 Army commissioned an analysis by the RAND Corporation of the Force Generation challenges faced by the Australian Army, which identified 25 key challenges to Army's strategic Force Generation, along with high level recommendations (Butler et al 2018). The report highlights challenges in areas such as prioritisation of roles and missions, operational tempo, force modernisation, human capital management, enablers, reserves and basing.

More recently, Army has outlined the challenge of Accelerated Warfare (Burr 2020), which recognises that the character of warfare is changing at a rate faster than existing processes, concepts, capabilities and structures were designed for. Army's response, called Army in Motion, accepts the requirement for continual change, positing that the Army needs to strike a balance between being ready now: to do more things, in more places, 
across more domains, while preparing to be future ready: preparing for future challenges and modernising the Army.

In parallel, Defence is making an unprecedented investment in modernising the Army. Within 10 years, Army will acquire new combat reconnaissance vehicles, infantry fighting vehicles and upgraded tanks, supported by a new fleet of transport and support vehicles. Soldiers will fight with a new combat ensemble with a new assault weapon. They will be supported by new specialist weapons, helicopters and artillery. They will be enabled and protected by new anti-air missile systems, engineering capabilities and autonomous systems from the tactical to strategic level. This new capability requires integration with Army, not only to familiarise operators with new equipment but to evolve concepts and procedures in order to use it to greatest effect.

To meet these challenges, Army has determined that the Force Generation system, which underpins the Army's ability to train and modernise, requires greater flexibility and agility. In mid-2020, Army established a working group to develop Force Generation options, and DSTG was approached to provide a rapid assessment of these options to identify strengths and weaknesses, along with the important factors requiring further analysis.

\section{METHOD}

Force Generation interacts with processes within the Australian Army, such as training, readiness and modernisation. These are in turn linked in a highly interdependent way to the various functions and requirements within the Army. Therefore, any changes to the Force Generation system are likely to have wide ranging effects across the wider Army. An ideal approach for modelling this system is some form of process model, such as a system dynamics model, where functions relevant to Force Generation are explicitly represented as practically as possible. However, this was deemed infeasible for two reasons; first, the Force Generation options under examination were in their formative design stages, lacking necessary detail to inform such a model; second, the study timeframe necessitated a more expedient approach in order to impact decision making. Therefore, a causal modelling approach, in the form of a hybrid Bayesian Belief Network (BBN) and Utility model, was used to analyse and investigate this problem. Bayesian models are an increasingly popular tool for facilitating and structuring data elicited from experts, as discussed in (Hassall et al, 2019), who notes that "this explosion in practical BBN modelling may in part be due to the relative simplicity of the intuitive graphical representation of multiple interrelated variables captured through conditional probabilities". The causal model structure provides an intuitive representation of Army functions relevant to Force Generation and their interdependencies. Consequently, this helps uncover reasoning and context which is useful to the researcher. For example, a question posed to an expert might ask:

\section{"If your acquisition program is behind schedule, and your ability to build collective competencies is high, what is the likelihood that your unit will be able to adequately modernise?"}

An expert can draw upon their experience and imagine such a situation, providing an assessment of the likelihood of a positive outcome. This use of Bayesian models in this way has support in the literature; Hassall et al (2019) discusses the practice in detail while Kuhnert et al (2010) provide a comprehensive guide to the approach for the ecological modelling context. This approach has been used by DSTG numerous times when addressing highly interdependent problems with a large amount of uncertainty (Coutts 2013, Cao et al 2013, Pietsch et al 2018). Typically, these studies adopt a campaign approach, where an array of analytical techniques and context setting activities are employed to build validity as described in (Bowden, 2013).

The anticipated structure of the causal model, henceforth called the Force Generation Options Assessment Model, was designed to trace the impact of Force Generation model changes through the relevant functions and organisations of Army, and ultimately to broad outcomes relating to Army's ability to achieve its missions. The model was constructed and populated in two phases; first, a model derivation phase, where the important factors and therefore underlying model structure were elicited; second, a data collection phase, where the potential impact of changes to the Force Generation system were captured and assessed. These phases are described in more detail in the following sections.

Data for both phases was derived and populated via Subject Matter Expert (SME) judgement workshops with a range of stakeholders across the Australian Army and Joint organisations, given Army's contribution to Joint. Wherever possible, multiple stakeholders with relevant expertise were engaged to provide as many relevant perspectives as possible for each node of the derived model. For example, given that changes to force generation will impact on how the Combat Brigades build their individual and collective competencies, we reached out to the Headquarters of each of $1^{\text {st }}, 3^{\text {rd }}$ and $7^{\text {th }}$ Brigades. Similar approaches were made to organisations across Army with relevant responsibility or knowledge, such as training, preparedness, Special Operations, Reserves, acquisition, Enablers, personnel and Joint integration. 
Each organisation approached was assigned one or more nodes of the causal model according to their perceived knowledge. This included the node itself, along with any other child nodes (nodes which have a direct relationship with the identified node). For example, we elicited data from $1^{\text {st }}$ Brigade regarding the ability to develop Individual and Small Team Competencies, which is their responsibility. In addition, we also elicited data from $1^{\text {st }}$ Brigade on the ability to develop Joint Collective Competencies, as the former influences the latter. Through this process, most nodes in our causal model ended up with conditional probability elicitations from several perspectives. Multiple judgements for a single node were averaged in the final model, with sensitivity analysis conducted on nodes with the greatest disagreement between participants.

\section{MODEL DERIVATION}

The Australian Army is a complex, interdependent system of approximately 47,000 (as of 2018) regular and reserve service personnel, supported by a large civilian workforce and partnering heavily with Defence Industry. The Force Generation system has fundamental links across the Army ecosystem, and therefore the Force Generation Options Assessment Model needed sufficient breadth to cover these effects.

To derive the model, we conducted structured interviews with 12 organisations and experts across the Army. Through these discussions, we identified numerous factors where changes to the Force Generation system would influence as either a first order effect or as a follow on effect. These factors were eventually organised into a hybrid BBN and Utility model with a total of 64 nodes. Although we cannot share the exact network itself, Table 1 shows the types of factors which were considered, along with the reasoning for their inclusion.

Table 1. Derived Factors in the Force Generation Options Assessment Model

\begin{tabular}{|c|c|}
\hline Factor & Description \\
\hline Force Generation Option & $\begin{array}{l}\text { The option under consideration, used as a decision node within the Bayesian } \\
\text { Belief Network. Four options were considered for the sponsor. }\end{array}$ \\
\hline Time Horizon & $\begin{array}{l}\text { Two time horizons were considered; on implementation (2022) and at the end } \\
\text { of a review period (2028). This also served as a decision node within the } \\
\text { network. }\end{array}$ \\
\hline Acquisition Programs & $\begin{array}{l}\text { Army manages an expansive array of acquisition programs, each with their own } \\
\text { decision timeframes, delivery schedules and costs. Introducing new equipment } \\
\text { requires time for familiarisation and training, which requires careful scheduling } \\
\text { around individual and collective training regimes. }\end{array}$ \\
\hline Combat Brigades & $\begin{array}{l}\text { Any changes to the Force Generation system will affect a Combat Brigade's } \\
\text { ability to generate ready elements, train and rest appropriately. }\end{array}$ \\
\hline Enabler Brigades & $\begin{array}{l}\text { Army maintains a number of specialist Brigades which have their own unique } \\
\text { rotation requirements, which will be impacted by changes to the Force } \\
\text { Generation system. }\end{array}$ \\
\hline $\begin{array}{l}\text { Special Operations } \\
\text { (SOCOMD) }\end{array}$ & $\begin{array}{l}\text { SOCOMD have unique readiness requirements which are influenced by the } \\
\text { Force Generation system. }\end{array}$ \\
\hline Reserves & $\begin{array}{l}\text { Today's Army Reserves house numerous unique capabilities and are often } \\
\text { called on for Domestic tasks; their unique requirements and part time nature } \\
\text { need to work with any Force Generation system. }\end{array}$ \\
\hline Cost & $\begin{array}{l}\text { Cost is divided into up-front cost, caused by changing the Force Generation } \\
\text { system, and ongoing sustainability cost. }\end{array}$ \\
\hline Personnel Tempo & $\begin{array}{l}\text { This factor relates to maintaining the appropriate level of commitment required } \\
\text { of personnel, in terms of training, operations and rest. This requires that a Force } \\
\text { Generation system appropriately schedule workload such that it avoids both } \\
\text { burnout but also manages periods of low tempo, both of which contribute to } \\
\text { staff attrition. }\end{array}$ \\
\hline Collective Competencies & $\begin{array}{l}\text { Army's key role is to prepare land forces for war, and building warfighting } \\
\text { competencies is a critical factor in achieving readiness for this role. A Force } \\
\text { Generation system must allow Army to train individually and collectively in a } \\
\text { coherent manner. }\end{array}$ \\
\hline
\end{tabular}


Evolving Concepts

As new capability is introduced through programs and modernisation, Army must have the ability to evolve how it intends to fight to best employ new systems.

Through extensive sponsor consultation, we derived five output measures which formed the output nodes of the model. These formed the high level requirements of an effective Force Generation system and are shown in Table 2. These in turn were combined into an overall effectiveness measure using an Additive Linear Utility node, with weights derived through a sponsor engagement workshop.

Table 2. High Level Measures of Force Generation System Effectiveness

\begin{tabular}{|l|l|}
\hline Measure & Description \\
\hline Affordability & $\begin{array}{l}\text { The likelihood that the Force Generation system will allow Army to operate within its } \\
\text { allocated budget. }\end{array}$ \\
\hline Sustainability & $\begin{array}{l}\text { The likelihood that the Force Generation system supports a sustainable personnel } \\
\text { tempo and therefore a manageable level of attrition. }\end{array}$ \\
\hline Readiness & The likelihood that Army will be able to meet its preparedness requirements. \\
\hline Responsiveness & $\begin{array}{l}\text { The likelihood that Army will have the agility to meet unforeseen demands. } \\
\text { Modernisation }\end{array}$ \\
$\begin{array}{l}\text { The likelihood that Army will be able to effectively integrate new equipment and } \\
\text { evolve concepts. }\end{array}$ \\
\hline
\end{tabular}

Figure 2 shows a representative model structure in conceptual terms. The Force Generation option and the time horizon form the inputs as decision variables, and are parents to a variety of nodes. These include individual soldier competencies, modernisation programs, personnel tempo, training and retention and finally cost. These impact on other factors, such as the ability to build collective competencies and the ability to evolve concepts. Ultimately, these are linked to the high level measures of effectiveness described in Table 2. Although we had no avenue for formal model structure validation, we gained reasonable confidence the relevant nodes and their effects were captured through extensive engagements with Army and DSTG experts involved in the design of the current Force Generation system, along with strong alignment with relevant literature discussing Force Generation, in particular (Breen, 2014) and (Butler et al, 2018).

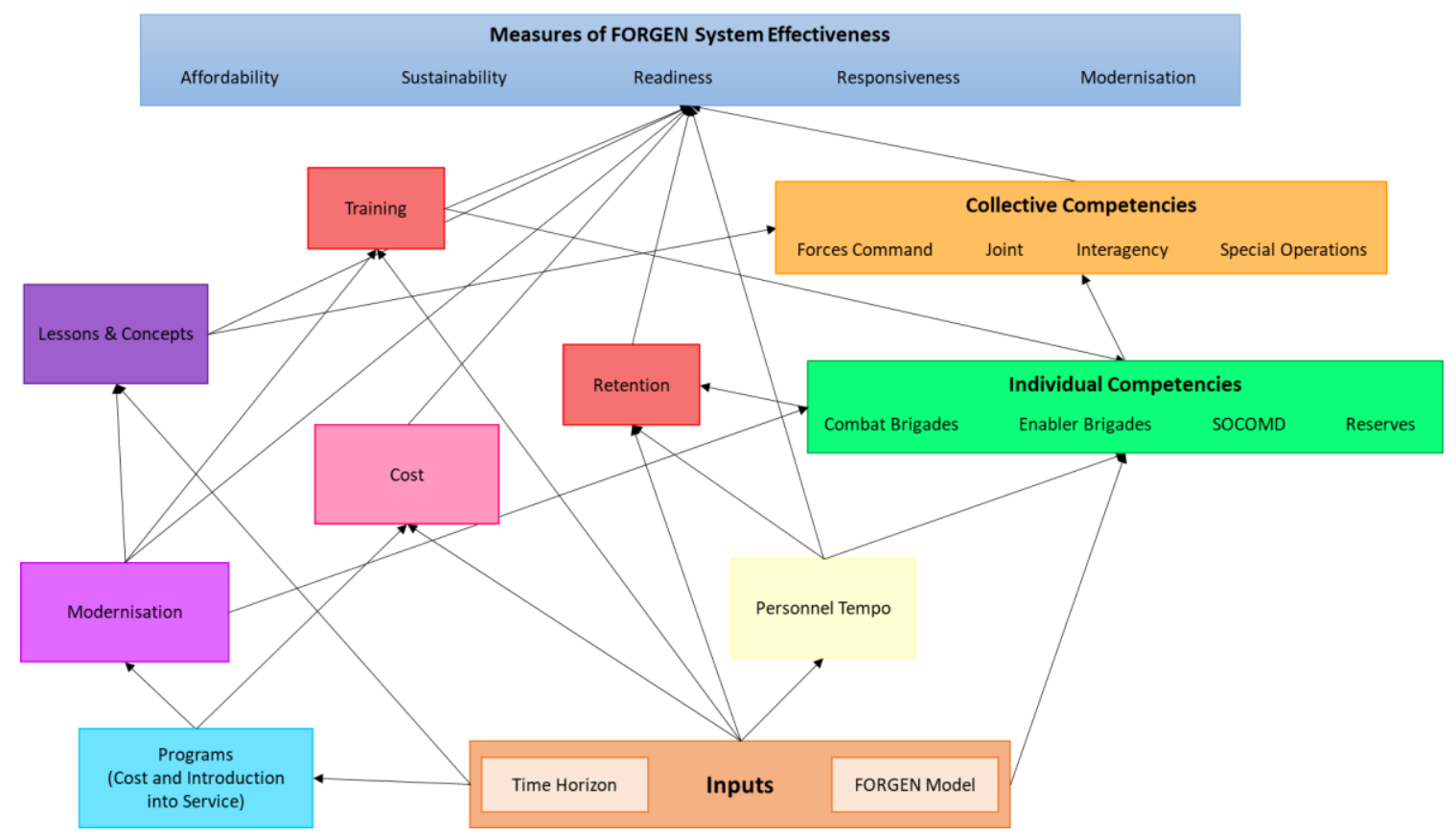

Figure 2. Force Generation Options Assessment Model 


\section{MODEL DATA COLLECTION}

The data collection phase of the study primarily comprised eliciting conditional probability tables to populate the BBN. As for the model derivation phase, a wide range of SME were engaged across Army. Given the size of the causal model, each SME was only required to complete data for selected nodes matching their role and expertise. In total, 25 organisations and experts from across the Army were engaged, which allowed for the collection of a range of perspectives for the most critical factors.

Due to travel restrictions imposed by the Covid-19 pandemic, all data collection was conducted via remote means, where previously our team had performed data collection in person using software designed by DSTG to assist. Instead, we rapidly developed data collection proforma based on an Excel worksheet. Given the size of the causal model, software was developed to automate the production of these data collection sheets (see Figure 3 for an example). In most cases, data collection was conducted collaboratively with SME, as the conditional questions often required significant discussion and debate to properly contextualise them.

In the example below, we are collecting data on the affordability measure. In this case the two parent nodes, that is those which directly influence affordability as identified in the model, are the cost of implementation and cost of conduct. Participants were asked to assess the likelihood that the Force Generation system was affordable for each combination of input states. For example, if both the input costs are low, the participant rated the likelihood of the Force Generation system being affordable as Very Likely. Phrase-based scales are used and then translated into Bayesian probabilities post activity.

In cases with more parent nodes, the number of input state combinations can start to increase significantly, and therefore an interpolation method proposed in (Cain 2001) is used, where by making certain independence assumptions one can reduce the number of input state combinations that are necessary to capture.

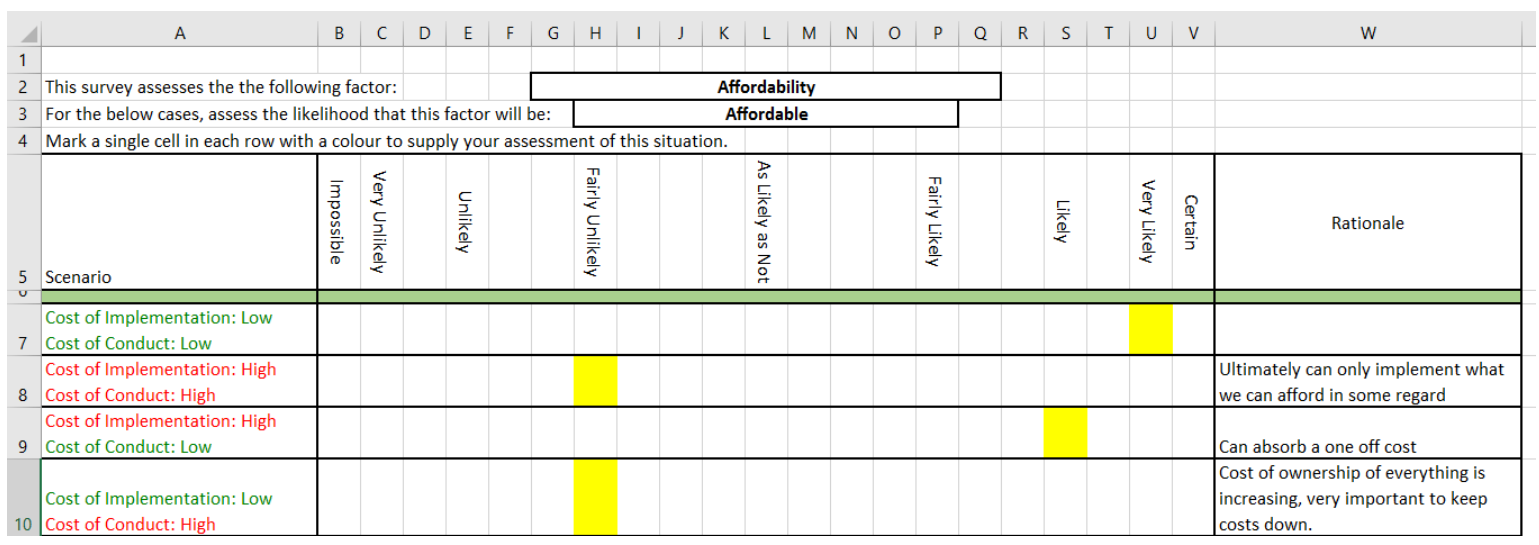

Figure 3. Conditional Probability Table Data Collection Proforma

\section{RESULTS}

The Force Generation Options Assessment Model was derived, populated and analysed within a period of approximately three months in 2020 to support the expedient timeframes required to influence decision making. Although the authors cannot publish either the options considered nor the results obtained, we can say that the model was able to both differentiate between options and identify critical factors requiring further attention by decision makers. It also proved a valuable, structured way for eliciting SME judgement.

This causal modelling approach proved to be appropriate given the timeframe required and the type of problem presented. Our team was able to rapidly build a representative model of the impact of changing Army's Force Generation system that was highly contextualised to our sponsor's particular problem. This is an important point; given more time, one would likely wish to employ either system dynamics or some other form of process modelling to understand how a Force Generation option influences Army organisations and functions over time. However, the requirement was to provide rapid, broad analysis of the impact of change in a fluid environment with only partially defined options. This meant that Bayesian-based causal modelling was an appropriate and feasible option, within the resource and time constraints, for providing timely evidence-based analysis for the decision maker.

Improvements in study execution could have been made. Given more time, the model data collection phase would have included revisiting SME as results were collected and the model updated, allowing for further refinement of likelihood scores and better elicitation of reasoning as they are exposed to other perspectives. 
Secondly, the scenario presented for this analysis was a generic, whole-of-Army context. Ideally, various contexts and functions would have been examined in bespoke ways, either through the same causal modelling approach or another method. For example, a scheduling optimisation approach might be applied to the use of training ranges under each Force Generation option.

This study was conducted in the second half of 2020 and therefore Covid-19 was a significant factor in the analysis conduct. A typical approach to this problem would entail one or more in person workshops for model construction, data elicitation and analysis. Instead, almost all of these phases of work were conducted remotely, through either phone, videoconference or via email. This made the data collection phase challenging, as eliciting a judgement-based conditional probability with numerous dependencies can be a challenging mental exercise and difficult to explain.

For this reason, DSTG are developing web-based data collection software which allows participants to fill in a conditional probability table in the form of a familiar survey-like interface. This software is designed to work directly with and interpret the supplied Bayesian Belief Network and implement the Cain interpolation methodology used for this study along with the ACE method described in (Hassall et al, 2019). Given that dislocated studies like this will be increasingly common in the near future, distributed data collection solutions, tied to specific methodologies, will be increasingly valuable.

\section{ACKNOWLEDGEMENTS}

The authors acknowledge the contributions of LTCOL James Murray and Dr Theresa Hay in sponsoring, guiding and supporting this body of work.

\section{REFERENCES}

Bowden, F. and Williams, P. (2013), A Framework for Determining the Validation of Analytical Campaigns for Defence Experimentation, 20th International Congress on Modelling and Simulation, Adelaide, Australia, 1-6 December 2013.

Breen, B. (2014), Preparing the Australian Army for Joint Employment: A Short History of the Adaptive Army Initiative 2007-2010, The Australian Army, ISBN 978-0-9874959-1-4.

Butler, D.M., Colabella, L.P., Thompson, J.A., Shrkin, M., Seabrook, S.B., Jensen, R., Burnett, C.B., 2018. Comprehensive Analysis of Strategic Force Generation Challenges in the Australian Army, RAND Corporation, ISBN 978-1-9774-0043-7

Burr, MAJGEN R., 2020. Army in Motion, Australian Army.

Cain, J., 2001. Planning Improvements in Natural Resources Management, Centre for Ecology and Hydrology, Wallingford, UK, 124.

Coutts, A. (2013), Balancing the Validity and Viability of Bayesian Belief Networks for the Study of National Strategic Decisions, 22nd National Conference of the Australian Society for Operations Research, Adelaide, Australia, 1 - 6 December 2013.

Cao, T., Coutts, A. and Lui, F. (2013), A Combined Bayesian Belief Network Analysis and Systems Architectural Approach to analyse an Amphibious C4ISR System, 22nd National Conference of the Australian Society for Operations Research, Adelaide, Australia, 1 - 6 December 2013.

Hassall, K. L., Dailey, G., Zawadzka, J., Milne, A. E., Harris, J. A., Corstanje, R. and Whitmore, A. P. (2019) Facilitating the Elicitation of Beliefs for use in Bayesian Belief Modelling, Environmental Modelling and Software, Volume 122, 2019, 104539, ISSN 1364-8152.

Kuhnert, P. M., Martin, T. G. and Griffiths, S. P. (2010), A Guide to Eliciting and Using Expert Knowledge in Bayesian Ecological Models, Ecology Letters 13: pp 900 - 914.

Pietsch, B., Schliebs, G. Kosowski, L. and Coutts, A. (2018), Development of a Cognitive and Physical Workload Model for a Dismounted Section Task, DST-Group-GD-1013. 